\title{
Um panorama da cartografia no Brasil: uma investigação a partir das teses e dissertações da Comunicação entre 2010 e 2017
}

An overview about cartography in Brazil: a research based on master theses and doctoral dissertations of the Communication between 2010 and 2017

Una visión general de la cartografía en Brasil: una investigación basada en tesis y disertaciones de comunicación entre 2010 y 2017

DOI: https://doi.org/10.1590/1809-5844202124

\author{
Nísia Martins do Rosário ${ }^{1}$ \\ https://orcid.org/0000-0003-3484-8029
}

\section{Paula Coruja ${ }^{1}$}

http://orcid.org/0000-0001-9870-1371

\section{Tiago Segabinazzi ${ }^{2}$}

https://orcid.org/0000-0003-2410-5520

${ }^{1}$ (Universidade Federal do Rio Grande do Sul, Faculdade de Biblioteconomia e Comunicação, Programa de Pós-Graduação em Comunicação. Porto Alegre - RS, Brasil).

${ }^{2}$ (Universidade do Vale do Rio dos Sinos, Escola da Indústria Criativa, Programa de Pós-Graduação em Comunicação. São Leopoldo - RS, Brasil).

\section{Resumo}

Neste artigo, buscamos esclarecer aspectos fundantes da cartografia e apresentar resultados de uma pesquisa que tem por objetivo investigar os modos de uso do método como aporte metodológico pela área da Comunicação no Brasil. Para tanto, apresentamos inicialmente um mapa desse método e examinamos o estado da arte a partir de teses e dissertações defendidas no período entre 2010 e 2017. É possível perceber, em algumas pesquisas, a adoção do termo como sinônimo de outros procedimentos metodológicos, bem como o uso superficial do arcabouço epistêmico-metodológico disponível. Foi possível identificar cinco perspectivas cartográficas que vêm ganhando destaque em função da base epistemológica empregada: a baseada em Deleuze e Guattari, a apoiada em Walter Benjamin, a Cartografia das Controvérsias (respaldada pela Teoria Ator-Rede), a apoiada nos estudos de Martín-Barbero e a cartografia poética proposta por Lucia Leão.

Palavras-chave: Metodologia de Pesquisa. Cartografia. Estado da Arte. 


\begin{abstract}
This article is aimed to clarify fundamental aspects and present the results of a research that objectives to investigate the procedures for using Cartography as a methodological approach for the field study of Communication in Brazil. Therefore, we initially present a map of the method and examine the state of the art from the theses and dissertations defended between 2010 and 2017 is examined. It is possible to observe the adoption of the term as a synonym for other methodological procedures, along with the superficial use of the available epistemicmethodological framework. It was possible to identify five cartographic perspectives gaining prominence due the epistemological foundation employed, as it follows: Deleuze and Guattari, Walter Benjamin, Cartography of Controversies (based on Actor-Network Theory), MartínBarbero and Lucia Leãos’s poetics cartography.
\end{abstract}

Keywords: Research Methodology. Cartography. State of Art.

\title{
Resumén
}

En este artículo, buscamos aclarar aspectos fundamentales y presentar los resultados de una investigación que tiene como objetivo investigar Las formas de utilizar el método como contribución metodológica del área de Comunicación en Brasil. Con este fin, inicialmente presentamos un mapa de este método y examinamos el estado del arte basado en las tesis y disertaciones defendidas en el período entre 2010 y 2017. Es posible percibir, en algunas investigaciones, la adopción del término como sinónimo de otros procedimientos metodológicos, así como el uso superficial del marco epistémico-metodológico disponible. Fue posible identificar cinco perspectivas cartográficas que están ganando importancia debido a la base epistemológica empleada: la basada en Deleuze y Guattari, la respaldada por Walter Benjamin, la Cartografía de controversias (respaldada por la Teoría del Actor-Rede), la respaldada por los estudios de Martín-Barbero y la cartografía poética propuesta por Lucía Leão.

Palabras clave: Metodología de la investigación. Cartografía. Estado del arte.

\section{Introdução: mapas da cartografia}

Mesmo que de forma ainda tímida, as perspectivas cartográficas de inspiração pósestruturalista vêm sendo adotadas por áreas diversas das Ciências Humanas no Brasil na última década, inclusive pelo campo da Comunicação. Seus usos díspares - já que se ancoram numa abordagem não-essencialista -, ainda causam debates e estranhamentos acerca dos procedimentos empregados e da sua legitimidade científica. Mais uma razão para problematizá-la.

O ponto mais importante para iniciar esse texto é reforçar a premissa de que, para pensar a cartografia, é necessário atualizar a perspectiva acerca do conhecimento científico e do método, conforme abordaremos a seguir. É importante afirmar, ainda, que muitos autores que estudam a ciência já vêm requalificando esses princípios e, portanto, não é exclusividade do ponto de vista cartográfico. 
O termo cartografia ${ }^{1}$ vem sendo ressignificado a partir da construção de um conhecimento conceitual configurado pelo pensamento pós-estruturalista, como fruto da crise da ciência moderna ${ }^{2}$ e como ponto de crítica de seus paradigmas. O pensamento cartográfico busca a desterritorialização e a desconstrução de modos de pensar e colocar em prática a ciência e a pesquisa (modernas). Compreender a ciência por essa via não é "fundá-la dogmaticamente em qualquer dos princípios absolutos ou a priori que a filosofia da ciência nos tem fornecido [...]. Ao contrário, trata-se de compreendê-la enquanto prática social de conhecimento, uma tarefa que se vai cumprindo em diálogo com o mundo [...]" (SANTOS, 1989, p. 13).

A preocupação com as condições de produção do saber é um dos princípios fundantes da cartografia: como evitar que a criação de um problema conduza sua resolução a priori; como criar conhecimento sem cercear o que ainda-não-é-conhecido? Uma das saídas propostas é a inversão da etimologia do termo método, de metá-hodos para hódos-metá, conforme Passos, Kastrup e Escóssia (2009, p. 10-11):

A metodologia, quando se impõe como palavra de ordem, define-se por regras previamente estabelecidas. Daí o sentido tradicional de metodologia que está impresso na própria etimologia da palavra: metá-hódos. Com essa direção, a pesquisa é definida como um caminho (hódos) predeterminado pelas metas dadas de partida. Por sua vez, a cartografia propõe uma reversão metodológica: transformar o metá-hódos em hódos-metá.

Mais potente do que saber de antemão onde pode chegar nossa problematização - por meio da proposta tradicional do método de predefinir o caminho - é deixar-se guiar pelo que o desenrolar da pesquisa sugerir, passo-a-passo. Esta reversão metodológica afirma a cartografia como uma atitude a ser assumida.

Numa das críticas mais radicais ao conhecimento moderno - feita do interior de uma “ciência dura”, de resultados práticos -, Feyerabend (1977) se mostra preocupado exatamente com o seguimento estrito de um método que conduza uma pesquisa, afinal, a história mostra que há violações não acidentais dos princípios científicos que levam ao progresso; deste modo, vê estas transgressões como necessárias ao avanço científico. Da mesma forma, ao entender os fenômenos a partir de uma complexidade multifacetada e imprevisível, Morin (2011) considera que o saber provém do aleatório - que não pode ser previsto.

1 Literalmente, o sentido mais imediato do termo cartografia está associado à geografia e à criação de mapas. Sua etimologia traz o sentido de "carta escrita" e, portanto, tem relação com mapas que visam a identificar superfícies, formas, curvas, volumes. Contudo, essa expressão foi sendo apropriada por outras áreas de conhecimento, tais como sociologia, filosofia, psicologia, educação e seus usos foram se adequando às reflexões trazidas por estudiosos e pensadores estabelecendo relações mais diretas com método e metodologias. 2 Para Santos (1989) há, atualmente, dois tipos de crise da ciência: do crescimento que se relaciona com a disciplina e com a insatisfação com métodos e/ou conceitos; e a crise da degenerescência - correspondente à ciência e aos paradigmas. 
O ponto de partida da cartografia, portanto, é o deslocamento, requerendo invenção e experimentação ${ }^{3}$ que não seguem modelos, mas exigem reflexão constante sobre o processo metodológico, operando na dissolução de pontos de vista instituídos. O rigor de uma pesquisa não é deixado de lado por conta disso: o método é traçado na experiência da investigação, enquanto o trajeto está sendo delineado e no encontro com o problema e com o objeto de pesquisa, a partir de uma constante reflexão sobre os processos ou, como afirmam Barros e Barros (2013, p. 384), “permitir constantemente que a própria pesquisa seja interrogada”.

Não há, portanto, a pretensão da verdade como conhecimento final - este é o problema da indução para Popper (2013) -, as inferências advindas de casos particulares não podem ser regras para enunciados universais. Ao indicar outros modos de fazer pesquisa, que requerem atualização do sistema do próprio investigador, a cartografia empreende mudanças de paradigmas - que, aliás, não estão distantes de correntes e pensamentos em vigência na comunicação.

Para ter atitude cartográfica, Passos, Kastrup e Escóssia (2010, p. 201) defendem um refinamento da percepção que não se estabelece sobre um saber acumulado ou à memória, mas ao “cultivo da atenção concentrada e aberta à experiência de problematização”. Nesse fluxo, surgiria um pesquisador modificado em relação ao seu estado original, ciente de que está produzindo realidade, levado por um compromisso ético e político.

A atitude científica, então, se realiza tanto na colheita de dados, como na apresentação e na organização cognitiva: estamos sempre no meio de um problema, os elementos que o compõem já existem no momento em que o percebemos, em que o denunciamos, em que o circulamos... por isso iniciamos sempre no meio. Por não conceber uma linearidade, uma causa-consequência, não há outro início a não ser o meio: dali o pesquisador-cartógrafo parte para se perder nos fragmentos, já que colecionar é sua tarefa. Esta coleção de fragmentos aparentemente díspares e irregulares é possível justamente por se rejeitar uma meta e a repetição como condição de percepção dos fenômenos.

“As ideias se relacionam com as coisas como as constelações com as estrelas”, disse Walter Benjamin nas Questões introdutórias de crítica do conhecimento, em sua tese Origem do drama barroco alemão (OTTE; VOLPE, 2002). As constelações não são formações naturais, mas imagens culturais, que variam conforme as épocas e civilizações. Por isso, o olhar constelar do pesquisador é um possível: não é a relação necessária, a explicação de causa-efeito entre os elementos, mas uma possibilidade de entendimento de um fenômeno ao se relacionar elementos que o compõem. "Nunca ideias justas, justo uma ideia”, conforme dizia Godard (DELEUZE; GUATTARI, 2011, p. 48).

Montar o mapa de entendimento de um fenômeno, portanto, é sempre uma visão provisória, afinal, a produção de conhecimento e a produção de realidade, nessa via, são inseparáveis. Estamos implicados na produção de conhecimento e isso questiona a dita

3 É uma prática que privilegia a experimentação - processo distinto de experiência, a imagem tradicional da prática científica que permitiria isolar fenômenos e, principalmente, reproduzir as reações num ambiente isolado como forma de falseabilidade. 
neutralidade desejada para a objetividade científica, para a separação entre teoria e prática, sujeito e objeto e até mesmo de conhecimento e política.

Pela consciência do olhar do pesquisador como constitutivo daquilo que observa, a cartografia não propõe coletar dados, mas produzi-los (KASTRUP, 2007). Isso quer dizer que os dados empíricos não estão, de fato, dados, mas se conservam enquanto possibilidades - uma potência que cabe ao pesquisador atualizar: a partir da força do encontro gerado. Uma atitude menos estratégica e mais tática, para encontrar o que possivelmente não se conhecia, mas “já estava ali”, em potência.

Esta abertura ao não-pensado é parte fundamental na colheita que privilegia uma seleção não-teleológica conforme coloca Benjamin (1987) e também na forma rizomática de Deleuze e Guattari (1995a, 1995b, 1996, 1997a, 1997b). É assim que se inclui na investigação não apenas as regularidades e as repetições, mas é possível agregar os achados minoritários, as singularidades, os desvios, as ocorrências mínimas, as irregularidades, as inflexões e, sobretudo, a identificação das linhas de força que se constituem entre todos os achados.

Benjamin privilegia idas e vindas, afastar, contemplar, e ver as conexões intertextuais. Ao formar as constelações, o observador de estrelas percebe quais elementos se destacam e que ligações poderiam ser estabelecidas entre eles. O flâneur, o conhecido personagem alegórico de Benjamin que vagueia meio descompromissado pela metrópole - descrevendo o que vê, mas principalmente se fascinando, se deixando tocar e sendo levado a caminhos não planejados, conforme Silveira (2002) - traz um dos princípios do pesquisador-cartógrafo.

O investigador, nesta abordagem benjaminiana, é um observador, mas também é um coletor-colecionador: torto, irregular, que recolhe coisas conforme elas lhe aparecem sem aparentemente haver um propósito - a exclusão da teleologia, da meta. Aquilo que lhe chama atenção é guardado sem um sentido prévio. Assim, o pesquisador, ao se deixar perder, é entornado diante de inúmeras coisas e possibilidades que colocam o dilema da importância de cada uma delas. Deixar-se afetar pelo objeto, não pela recorrência ou abundância de determinada lógica, mas pelo grau de interesse que desperta, conforme Costa (2014, p. 73): “a condição para selecionar o que fará parte de sua pesquisa é a força do encontro gerado”.

Deleuze e Guattari (1995a, 1996, 1997a) constroem uma metalinguagem que é apropriada por outros autores e permite conceber um pensamento reorganizador do fazer científico, bem como reorientação de conceitos, modo de entender a ciência, processos científicos e até mesmo a vida. Entre os conceitos mais relevantes estão: rizoma, platôs, territorialização, desterritorialização, linhas de segmentaridade, linhas de fuga, multiplicidade, singularidades, heterogeneidade, devir. Para eles, a cartografia se constitui como um dos princípios do rizoma ${ }^{4}$ que se atualiza num mapa. Para os autores, tal mapa tem potencial para ser produzido a partir dos princípios do rizoma e, assim, permite que

4 Em Deleuze e Guattari (1995a) o rizoma tem seis princípios: conexão, heterogeneidade, multiplicidade, ruptura a-significante, decalcomania e cartografia. 
os pontos de intensidade das linhas de segmentaridade sejam mostradas, mas também as linhas de fuga e, principalmente, as conexões que se engendram entre elas. "Tais linhas vão articulando uma tessitura em sua própria velocidade de escoamento, provocando agenciamentos de diversas ordens, gerando diversidade de fluxos e, por fim, compondo mapas moventes” (ROSÁRIO, 2016, p. 188).

A Teoria Ator-Rede (TAR) defendida por Latour (2012) também se presta a pensar aspectos da cartografia a partir de diversos tipos de controvérsias em diferentes campos do conhecimento. Um dos princípios básicos da TAR é a importância equânime de atores humanos e não-humanos nos processos sociais, sendo este tipo de cartografia uma forma de mostrar a aplicação desta teoria na pesquisa social. Nessa via, Latour (2012) entende que a cartografia tem como território o mundo social, sendo que o plano de uma formiga é o melhor para mirar o universo da pesquisa, porque permite aproximar ao máximo de coletivos e redes. Esse processo habilita para a constituição de um 'guia de viagem' que possibilita acompanhar a reagregação dos actantes e que outorga a construção de paisagens desiguais, discrepantes por meio da 'deriva'.

Depois desse primeiro panorama, apresentaremos, a seguir, dados elaborados empiricamente a partir de investigação sobre os usos da cartografia no campo da Comunicação no Brasil, em teses e dissertações, num período de oito anos. Na terceira seção, traremos ponderações sobre a paisagem construída para esse método com base nos dados levantados, problematizando modos de uso e averiguando suas potencialidades, bem como apontando cinco perspectivas de abordagem que foram identificadas - diferenças; controvérsias; benjaminianas; poéticas; barberianas - explicando mais detidamente as duas primeiras. Por fim, as considerações finais defendem a cartografia como alternativa potente a pontos de vista teórico-metodológicos já existentes.

\section{$O$ vislumbre da paisagem}

É relevante o fato de que o campo da Comunicação tem dedicado atenção a estudar não só os fenômenos comunicativos, mas também os modos pelos quais as pesquisas se desenvolvem no âmbito teórico e empírico, um indicativo da maturidade na área. Em 2011, Aguiar ${ }^{5}$ já pesquisava o estado da arte da cartografia e entendemos que é importante dar continuidade a pesquisas como essa a fim de estender, complementar e atualizar as informações sobre práticas metodológicas na comunicação. Além de ser uma forma de dialogar com o próprio campo, é central em função de manter o registro das trajetórias que acompanham essas mudanças no desenvolvimento da ciência no Brasil.

5 Lisiane Aguiar defendeu sua dissertação no início de 2011 no Programa de Pós-Graduação em Ciências da Comunicação da Unisinos (http://www.repositorio.jesuita.org.br/handle/UNISINOS/2997). Realizou uma pesquisa da pesquisa sobre os usos da cartografia de Deleuze e Guattari em teses e dissertações. Uma das conclusões que consideramos importante foi que parte das teses e dissertações analisadas traziam a construção de um teoricismo abstrato, tornando a questão metodológica ainda muito incipiente. 
Assim, propusemos uma investigação que visa mapear e problematizar os usos da cartografia na área, no Brasil, e refletir sobre suas potencialidades. Para atingir a meta, optamos por explorar a produção bibliográfica de pesquisadores da comunicação que usam a cartografia, buscando identificar tendências e perspectivas sobre como ela é fundamentada e desenvolvida. Inicialmente, dedicamos nossa atenção às produções do corpo discente dos programas de pós-graduação brasileiros, considerando teses e dissertações a partir de 2010 até $2017^{6}$.

A revisão de literatura foi uma das primeiras etapas do processo (FLICK, 2009), uma vez que permite o vislumbre de potencialidades do objeto e um panorama dos usos teóricos e metodológicos. Dessa forma, esses dados funcionam como um sistema de informações (GALINDO CÁCERES, 2001) capaz de mostrar conjunturas, perspectivas e auxiliar na delimitação de aspectos fundamentais da pesquisa. $\mathrm{O}$ tipo de pesquisa que empreendemos aqui, portanto, se constitui entre os chamados estados da arte e a pesquisa da pesquisa. Essa última, segundo Bonin (2008), se constitui em um modo de pesquisar que permite o contato com determinadas produções que permitirão novas investigações e avanços a partir dele.

Num primeiro momento, apresentaremos os resultados quantitativos da investigação a partir de informações específicas retiradas das teses e dissertações, fazendo considerações sobre os dados levantados num viés qualitativo.

Para tanto, fizemos um levantamento a partir das teses e dissertações dos programas de pós-graduação em Comunicação do Brasil, pesquisando o banco de teses da Capes (atualizado a partir de 2013) e o banco de dados disponibilizado pelo Núcleo de Pesquisa Cultura e Recepção Midiática da UFRGS, que forneceu dados a partir de $2010^{7}$. Nos dois bancos de dados, realizamos a busca pela palavra "Cartografia" ${ }^{8}$ " presente em títulos, resumos e palavras-chave, o que resultou em 139 teses e dissertações ${ }^{9}$ na área da Comunicação.

Como podemos ver no gráfico a seguir (Gráfico 1), há um crescente interesse no período estudado por empregar um viés cartográfico às pesquisas, visto que estavam presentes em quatro trabalhos em 2010 e 39, em 2017.

\footnotetext{
6 Esse período foi definido em função da acessibilidade de teses e dissertações. O banco de teses da CAPES está atualizado a partir de 2013 e, com pesquisa complementar já existente (Disponível em: https://cedap.ufrgs.br/jspui/handle/2050011959/1091), conseguimos estender o período inicial para 2010. O desdobramento da pesquisa atingirá outros estratos, alcançando as produções acadêmicas registradas em livros e artigos científicos da área. Dessa forma, ainda que, no âmbito geral, os resultados trazidos para este texto sejam parciais, com o material analisado já foi possível delinear modos de uso da cartografia nesse segmento, o que poderá redundar ou não no desenvolvimento das outras etapas da pesquisa.

7 Disponível em: https://cedap.ufrgs.br/jspui/handle/2050011959/1091. Acesso em: 2 fev. 2019.

8 Além de palavras relacionadas, como cartográfico, cartógrafo etc.

9 Tomamos como base a lista de programas de pós-graduação listada na página da Compós. Salientamos, no entanto, que do total de programas atuais, nem todos tinham teses e/ou dissertações defendidas e disponibilizadas nos sites dos programas ou da Capes. A lista de programas está disponível em: http://www.compos.org.br/programas.php. Acesso em: 2 fev. 2019.
} 
Gráfico 1 - Total de trabalhos que trazem viés cartográfico por ano

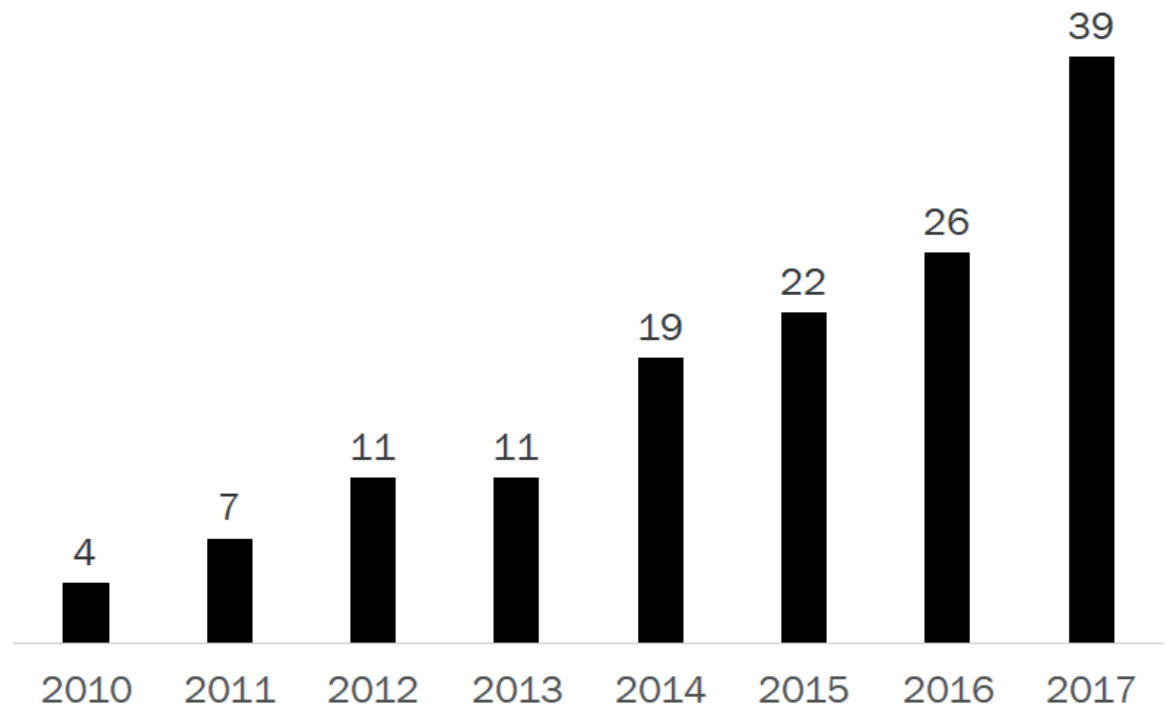

Fonte: as autoras.

Entre os 139 trabalhos, 85 são dissertações e 54, teses, como mostra o Gráfico 2:

Gráfico 2 - Trabalhos que trazem viés cartográfico por tipo de trabalho

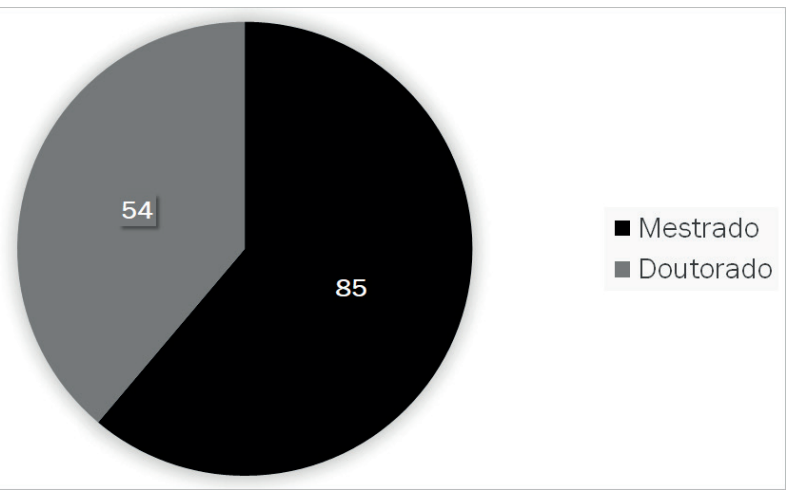

Fonte: as autoras.

Olhando outros dados referentes a esta produção, vemos, por exemplo, que 33 programas (Gráfico 3) geraram pesquisas com algum viés cartográfico. Os programas estão distribuídos em todas as regiões do Brasil (Sudeste - 15 programas, Sul - 7, Nordeste - 6, Centro-Oeste - 3, Norte - 2), com maior concentração na região Sudeste, onde há um maior número de PPGs. 
Gráfico 3 - Trabalhos que trazem viés cartográfico por universidade

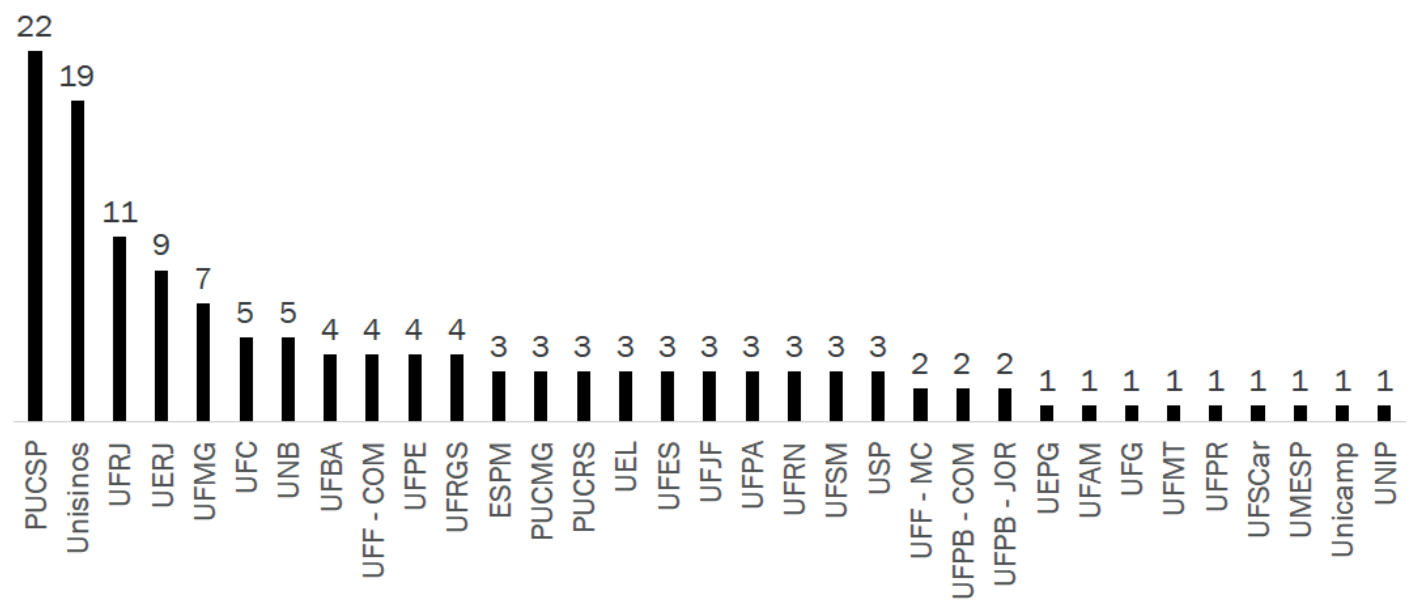

Fonte: as autoras.

Acessando os dados sobre orientação, vemos que apenas 12 professores orientaram mais de dois trabalhos, somando 48 teses e/ou dissertações (Gráfico 4), o que equivale a $34,53 \%$ do total da produção identificada. Isso já aponta brevemente para os dados que veremos a seguir, mais qualitativos, sobre como os discentes fizeram uso de referências cartográficas. No gráfico a seguir, podemos ter alguns indicativos da afinidade com certos referenciais teóricos e metodológicos, além de objetos de estudo, a partir da identificação dos orientadores.

Gráfico 4 - Trabalhos que trazem viés cartográfico por orientador/a

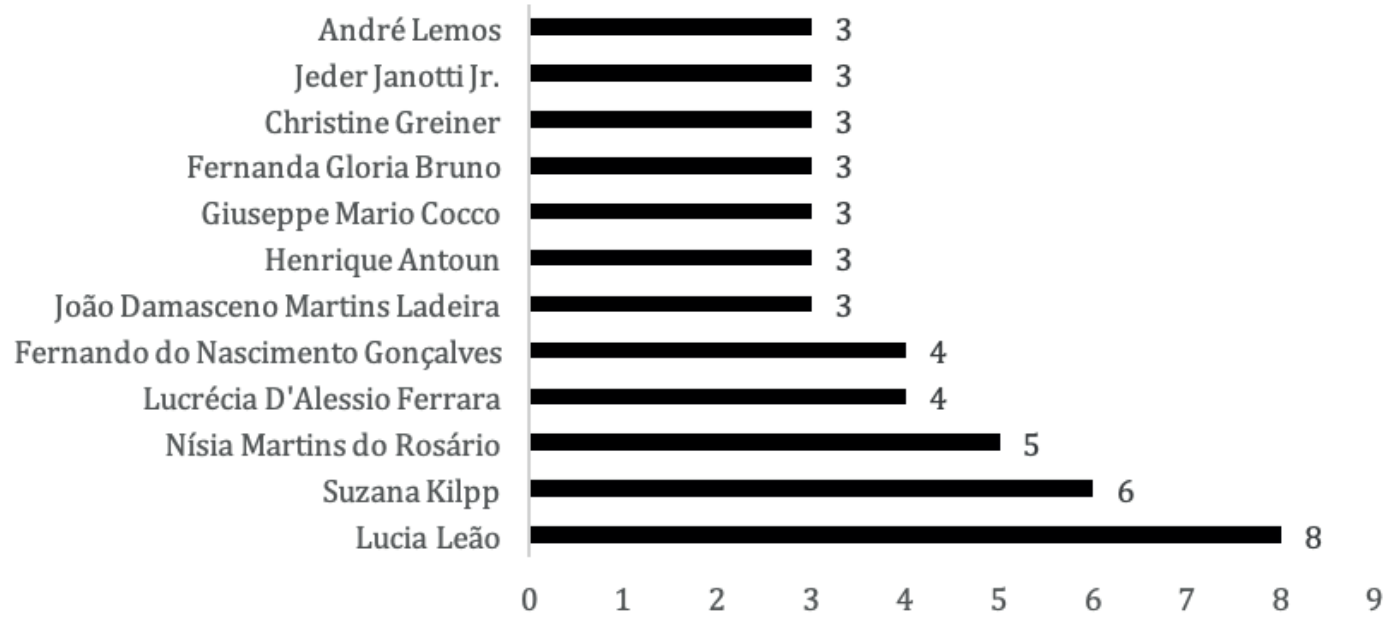

Fonte: as autoras. 
Além desses pesquisadores do Gráfico 4, identificamos dez professores de pósgraduação que acompanharam dois trabalhos e 71 que orientaram apenas um. Esse quadro totaliza 91 orientadores, indicando a diversidade do uso da cartografia tanto no que se refere a orientadores quanto no que se refere às instituições.

Entre todos os trabalhos analisados na pesquisa, alguns apresentavam mais claramente a cartografia atrelada a um referencial teórico metodológico específico (Gráfico 5), como é o caso da Cartografia das Diferenças, que tem o uso inspirado em Deleuze e Guattari, ou dos teóricos da Teoria Ator-Rede com a Cartografia das Controvérsias. Também se mostraram as constelações preconizadas por Benjamin, a cartografia poética, desenvolvida por Lúcia Leão, e a postura “de cartógrafo” por influência da obra de Martín-Barbero. Além disso, outros aportes, mais pulverizados, apareceram guiados por metodologias inspiradas na Geografia, Engenharia Cartográfica ou combinações pontuais entre as metodologias apresentadas anteriormente.

Gráfico 5 - Trabalhos que trazem viés cartográfico por tipo de abordagem teórica

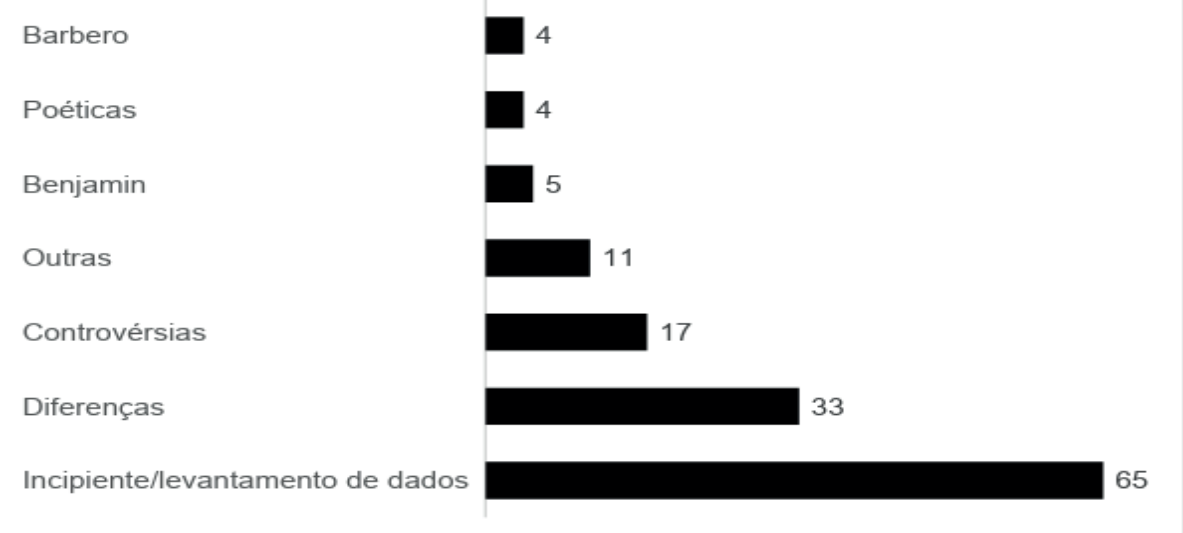

Fonte: as autoras.

O que mais chamou atenção, entretanto, foi a quantidade - 65 trabalhos, que equivale a 46,76\% do total - de teses e dissertações que usavam a palavra cartografia como sinônimo para diversos tipos de "levantamentos de dados" feitos durante o processo de pesquisa, mas sem uma fundamentação metodológica que justificasse o uso. Entre estes, também estão os trabalhos que afirmavam que fariam uso de cartografia, contudo, no seu desenvolvimento, não traziam referência alguma a viés ou a procedimento que se associasse à metodologia cartográfica, ou, então, o faziam de forma muito incipiente.

Isso mostra que, mesmo tendo um interesse crescente, ainda é preciso trabalhar melhor conceitualmente a questão para que a cartografia, como metodologia ou método, de fato oriente o fazer da pesquisa quando adotada. 
Sabemos que alguns trabalhos podem não ter sido incluídos por não trazerem palavraschaves, resumo ou título relacionados à cartografia entre os itens principais disponíveis para busca. Isso desperta uma reflexão não somente no sentido de apontar limites para esta pesquisa, mas em salientar a importância da elaboração de resumos e títulos que deem conta de todos os aspectos considerados fundamentais nos trabalhos. Quando trazidos de forma clara, auxiliam outros pesquisadores e pessoas interessadas a não só encontrarem os trabalhos, mas a ter uma dimensão mais clara do desenvolvimento da investigação.

\section{Considerações sobre uma paisagem}

Conforme apresentado na seção anterior, quase metade dos trabalhos estudados promete ou dá indicações de que a cartografia faz parte da pesquisa num viés metodológico voltado para o procedimento empírico, contudo, ela não é abordada no relatório teórica ou metodologicamente. Em muitos casos, o termo aparece como sinônimo de mapeamento, levantamento de dados ou pesquisa exploratória. Ao que parece, apenas configurando-se como uma outra denominação para procedimentos já existentes e que tornam superficial a sua utilização. Nesse sentido, é importante reiterar que as formulações sobre cartografia atualizadas para ciências sociais e humanas nas últimas décadas são concebidas a partir de um viés epistemológico que pode ser chamado de pós-estruturalista e, portanto, não basta que a metodologia seja cartográfica, a compreensão de ciência, de método, de modo de fazer pesquisa também precisam caminhar nessa direção.

O quadro capturado pela nossa investigação de uso insuficiente da cartografia pode inspirar pelo menos quatro suposições que não se excluem mutuamente e que, necessariamente, não se restringem a esse método: a) descaso com as teorias acionadoras da metodologia (BRAGA, 2011); b) uso indiscriminado e superficial do termo como parte de um modismo; c) desconhecimento dos fundamentos teóricos e epistemológicos desse conceito na atualidade; d) incompreensão das propostas desenvolvidas cientificamente apesar da imersão nelas. Em qualquer desses estratos mostra-se a necessidade de aprofundamento e problematização científica do método.

Mesmo em pesquisas que estão mais comprometidas com a fundamentação, há casos de tratamento escasso da teoria e de aplicação ao empírico, o que torna a metodologia precária. Alguns investigadores, entretanto, empenham-se em propor um percurso metodológico que mostra reflexão sobre o processo realizado, bem como apresentam o seu percurso na busca pelas pistas mostradas pelo território. Todos esses procuram, de certa forma, construir sua metodologia, propor caminhos renovados para o campo, configurar olhares singulares e alguns arriscam-se em resultados inesperados, sempre em justaposição com os indicativos dos autores utilizados.

Na via da fundamentação teórica, nossos apontamentos revelaram uma diversidade de autores que serviram como base ou que foram apontados como capazes de sustentar, 
ou pelo menos amparar, a perspectiva teórica e metodológica da cartografia. Conforme explicitamos no Gráfico 5, a partir das análises dos trabalhos e de articulações entre eles, foi possível identificar cinco enfoques mais organizados de cartografias: das diferenças; das controvérsias; benjaminianas; poéticas; e barberianas.

Ainda que se apresentem enfoques distintos da cartografia, não encontramos uma fidedignidade exclusivas aos autores de cada linha, alguns deles transitam pelos apanhados teóricos de várias teses e dissertações. Por exemplo, Foucault (1993, 1996, 2006) pode ser um autor inspirador do pensamento cartográfico por diversas perspectivas, tendo em vista seus estudos sobre ética e política, potência da vida, conhecimento crítico-criador, campo de forças, vontade de verdade e vontade de saber, entre outros.

Martín-Barbero (2004), teórico da comunicação que pensa a mais tempo sobre cartografia e, inclusive, escreveu o livro Ofício de Cartógrafo, é chamado a todo o momento nas investigações analisadas. $\mathrm{O}$ autor relata suas pesquisas e inspira muitos cartógrafos na comunicação, opera sobre mapas cognitivos, propondo mapas noturnos que seriam capazes de "indagar a dominação, a produção e o trabalho, mas a partir do outro lado: o das brechas, o do prazer. Um mapa (...) para mudar o lugar a partir do qual se formulam as perguntas para assumir as margens não como tema, mas como enzima” (MARTÍN-BARBERO, 2004, p. 18). Assim, ele rejeita mapas sínteses e propõe mapa do tipo arquipélago (congregando ilhas múltiplas).

Também Benjamin (1987) é convocado para contribuir com teses e dissertações centradas em enfoques que não são especificamente o dele, mas sua metalinguagem é utilizada com termos como: flaneur, constelações, mapas, colecionador, memória, arquivos. O autor deixou muitas pistas cartográficas em suas obras, voltando-se para a reflexão da postura metodológica, da construção do seu método, relatando suas imersões no campo. Os objetos de estudo escolhidos pelo filósofo alemão também são inspiradores, já que ele preferia bordéis, bancos de praças e cemitérios, ou seja, dava relevância a paisagens marginais. Suas considerações críticas ao positivismo e ao historicismo, bem como a abertura ao olhar fragmentário, heterogêneo, ensaístico e a valorização às “ruínas” se encaixam num movimento mais amplo pelo qual passam as ciências humanas e sociais de crítica à modernidade.

Na mesma linha, vêm Deleuze e Guattari com uma metalinguagem própria que já foi citada anteriormente. Principalmente nos cinco volumes de Mil Platôs (1995a, 1995b, 1996, 1997a, 1997b), mas também em outras obras - eles são os inspiradores da cartografia das diferenças. A apropriação de suas obras levou outros autores a desenvolverem um pensamento cartográfico que repensa o conceito de método entre outros. No Brasil, são muitos os pesquisadores que se destacam, no entanto, apontamos primeiramente a psicanalista, professora e pesquisadora Rolnik (2006) que, inclusive, escreveu Micropolíticas: cartografia do desejo (1996) ${ }^{10}$ juntamente com Guattari. A autora está presente na maioria dos trabalhos analisados que utilizam a vertente das Diferenças.

10 Em 1982, Suely Rolnik acompanha a vinda de Guattari ao Brasil. Juntos escrevem: Micropolítica. Cartografias do desejo. A partir daí, a autora se torna uma referência sobre cartografia, principalmente na área da psicologia e educação. Rolnik passa a trabalhar a cartografia como um método. 
Como são muitos dados levantados, não será possível compartilhar todos aqui. Assim, decidimos aprofundar mais apenas nas perspectivas cartográficas mais usadas: das Diferenças e Teoria Ator-Rede.

Pelo nosso levantamento (Gráfico 6, a seguir), encontramos teses e dissertações que trabalham com a cartografia das Diferenças desde o ano de 2010 e a cronologia aponta certa oscilação no número anual delas. Contudo, de modo geral, é possível constatar uma linha de crescimento que registra duas pesquisas em 2010 e nove em 2017. Ao todo, localizamos 33 trabalhos $^{11}$ com esse enfoque, sendo 14 de mestrado e 19 de doutorado, os quais estão distribuídos em programas da área de Comunicação de 12 universidades.

Gráfico 6 - Trabalhos que utilizaram a Cartografia das Diferenças por ano

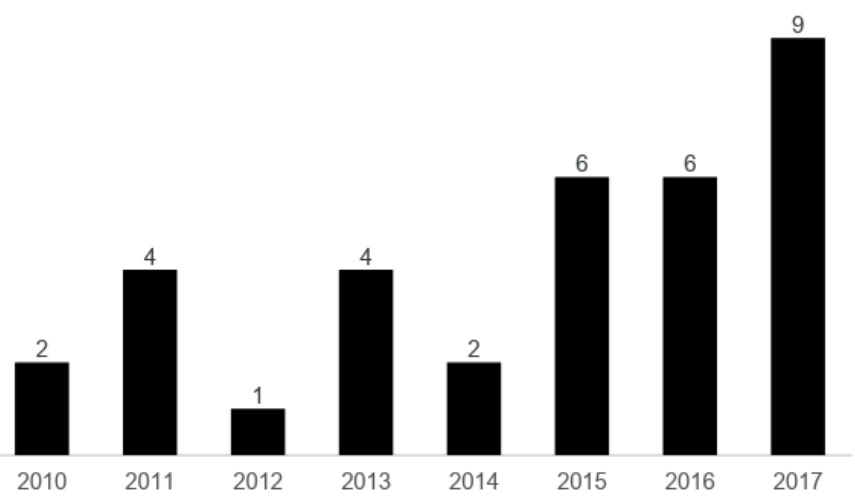

Fonte: as autoras.

O Programa de Pós-Graduação que mais se destaca pelo uso da cartografia das Diferenças é o de Ciências da Comunicação, da Unisinos, reunindo oito trabalhos (quatro de mestrado e quatro de doutorado) sob orientação de seis professores. Em seguida, vêm UFMG e UFRJ, ambas com quatro trabalhos no período, e ambas com uma tese e três dissertações; na primeira universidade, são três professores orientadores para as pesquisas e, na segunda, dois orientadores. Na UERJ, encontramos uma tese e duas dissertações e, na sequência, estão seis universidades que apresentaram dois trabalhos cada (UFF, PUC-SP, UFRGS, UFSM, PUC Minas, PUC-RS) e, por fim, duas IES com apenas um trabalho (UNB, UEL). Nossa investigação também levantou as subáreas de abordagem da cartografia no território da comunicação, mas não serão apresentadas aqui em função de tantas pluralidades de temas.

O impasse metodológico que se mostrou de forma geral nas pesquisas estudadas também se apresentou no uso da cartografia das Diferenças. Anteriormente, observamos

11 As referências completas estão disponíveis em: http://corporalidades.com.br/site/2019/02/20/2054/. Acesso em: 26 maio 2020. 
que a cartografia estimula a encontrar um caminho metodológico próprio, sendo que o que determina o método efetivamente é o próprio processo de investigação, o percurso. Esse é um movimento de muito esforço, sobretudo para pesquisadores em início de carreira e que estão sendo avaliados diretamente por seus trabalhos (mestrandos e doutorandos). Convivemos, ainda, com o paradigma do método que se constitui pela organização de um determinado modo de agir do cientista mediante modelos que colocam à parte tudo que não é da ordem do cientificamente validado.

Na análise qualitativa dos trabalhos, foi possível perceber que uma parte dos pesquisadores se dedicou a encontrar um caminho singular, adequado a seu objeto de investigação, sem, necessariamente, abandonar procedimentos usuais na comunicação e que se mostravam adequados. Na mesma via, também foi possível perceber que essa é uma tarefa que exige criatividade e inventividade conforme defendem Rolnik (2006), Kastrup (2008) e outros. Nas teses e/ou dissertações, encontramos propostas de: depoimentos, saberes militantes do pesquisador, mapas visuais, mapas descritivos, séries, configuração de platôs, apresentação de rizomas, entre outros. É preciso lembrar que, juntamente com essas novidades, estavam também entrevista, história de vida, análise de discurso, análise de imagens, observação participante, grupo focal.

Por fim, é importante relatar os modos da construção da fundamentação teórica da cartografia das Diferenças. Sem dúvida, identificamos maneiras distintas de tratamento conceitual-teórico. A primeira constatação é de que um grupo se aprofundou mais que outro, inclusive, inserindo um capítulo ou parte de um capítulo inicial para sustentar o seu método e percurso metodológico. Isso significa incluir, também, a pesquisa bibliográfica da cartografia nesse âmbito. Essas teses e dissertações não fazem uma defesa fechada, mas encaminham para pensar a cartografia como método. Outro grupo, entretanto, pareceu entender a cartografia como um procedimento metodológico e a incorporou apenas no capítulo empírico.

Os autores mais citados foram Deleuze e Guattari, sendo que, em algumas teses e dissertações, foram mencionados apenas para denominar o tipo de cartografia e, em outras, operaram efetivamente no quadro teórico. A partir dos dois filósofos, uma grande maioria dos investigadores embasou-se no grupo proveniente da psicologia e que se dedicou primeiramente ao desenvolvimento desse enfoque no Brasil. São representativas: Rolnik, Kastrup, Escóssia, Barros e Passos ${ }^{12}$. Porém, alguns pensadores que não são identificados diretamente com a cartografia das diferenças foram trazidos para complementar a configuração teórica, tais como: Martín-Barbero, Foucault, Benjamin, Latour - os quais também operam sobre perspectivas de mapas e cartografias - e, ainda, Marcondes Filho, França, Rossiter, Harley.

A Teoria Ator-Rede (TAR), de Bruno Latour, nos últimos anos, tem sido bastante utilizada para o estudo de conflitos e divergências em ambientes digitais. "Para a TAR,

12 Não citaremos nesse artigo as referências de todas as obras usadas desses autores porque são várias, inclusive algumas escritas em coautoria, e entendemos que não são fundamentais para a compreensão da nossa investigação. 
ambientes onde há controvérsia são ideais para a análise da formação de estruturas sociais: elas evidenciam atores, relações e agências que de outra forma poderiam passar despercebidas” (PEREIRA; BOECHAT, 2014, p. 558). A abordagem se atenta ao que escapa da sociologia estruturalista, ampla; ao invés de observar os macroprocessos do social, se concentra nos mediadores para descobrir suas características de fluxo, provisórias, em relação, conforme explica Lemos (2012, p. 36): “antes que seus atores assumam posições estáveis, resolvam suas polêmicas e terminem em 'encaixapretamento””.

A estabilização é a tendência das associações entre os actantes - "humanos” e "não-humanos" - da rede e o resultado do social em fluxo, após as controvérsias - neste momento é que a TAR se debruça, para perceber como posições morais, interpretações conflituosas ou mal-entendidos se apresentam e quais encaminhamentos podem gerar antes da criação de uma "caixa-preta”. Como nas mídias sociais são deixados rastros a partir da interação ao vivo, é possível de se cartografar as controvérsias em movimento e perceber a formação das redes que compõem o social - considerado sob a perspectiva de uma ontologia plana, que não diferencia humanos de não-humanos: há simetria, uma equivalência, entre estes actantes.

Assim, identificamos em nossa investigação que são agregados um conjunto de procedimentos de pesquisa, como a análise de discurso, de conteúdo, de redes sociais e observações de grupos, para mapear, explorar e visualizar polêmicas que levem em conta a agência de atores humanos e não-humanos. Como é possível visualizar no gráfico a seguir (Gráfico 7), nos estudos da Comunicação o interesse por esse enfoque cartográfico é recente, aparecendo nas defesas a partir de 2014, mas crescente, somando 17 trabalhos $^{13}$.

Gráfico 7 - Trabalhos que utilizaram a abordagem da Cartografia das Controvérsias, por ano

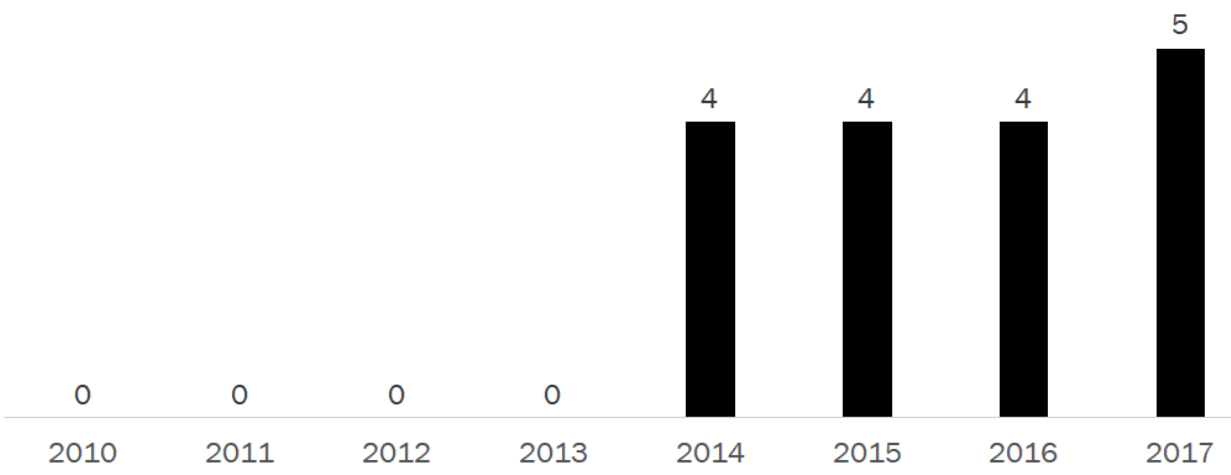

Fonte: as autoras.

13 As referências completas estão disponíveis em: http://corporalidades.com.br/site/2019/02/20/2054/. Acesso em: 20 fev. 2019. 
Entre os estratos dos trabalhos há um equilíbrio, com nove dissertações e oito teses. Apenas UFRJ, UFPE e USP têm mais de uma pesquisa defendida: quatro, dois e dois, respectivamente. As outras universidades com pós-graduandos em Comunicação que utilizaram esse aporte metodológico foram UFMG, PUC-SP, UFES, ESPM, UEL, UFG, UFPB (Comunicação e Cultura Midiáticas e Jornalismo), e UFBA com um trabalho em cada curso.

Um dos pontos em comum entre os trabalhos que optaram por esse referencial metodológico é a ausência de um modelo pré-estabelecido para mapear as controvérsias em rede. Entre os trabalhos, boa parte faz uso de ferramentas digitais para a coleta e análise de dados, principalmente aqueles com grande volume de informações. Nesta fase, alguns softwares e scripts aparecem com alguma recorrência, como o Ford Parse, Netvizz, Issue Crawler, Octoparse, QDA Miner e Hyphe. Para visualizar redes, Gephi é o programa mais conhecido. Outras ferramentas, com funções de busca específicas, também são citadas, como o Google Trends, para visualizar assuntos mais discutidos na internet, e o Google News Scraper, para a busca de notícias. Essas ferramentas auxiliaram no trabalho de busca por rastros digitais de controvérsias e de conexões entre as redes mapeadas pelos pesquisadores.

Como é uma proposta que recentemente começa a ser usada na Comunicação, com relativamente pouca literatura sobre o assunto, vemos uma repetição também dos referenciais que embasam os capítulos metodológicos que tratam desse tipo de cartografia. Além do próprio Latour, principalmente a obra Reagregando o Social: uma introdução à teoria do Ator-Rede, Venturini (2010, 2012) e Lemos (2013, 2016) são os autores mais citados. Mesmo que existam repetições das falas desses autores entre as pesquisas, é comum vermos diferentes etapas dessa cartografia sendo nominadas de forma diversa, ainda que com significados semelhantes.

\section{Considerações finais}

De modo geral, nossa pesquisa detectou variados modos de abordagem do pensamento cartográfico na comunicação, revelando que este método não se constitui a partir de um viés teórico apenas e, principalmente, que ainda está em processo de composição, e sobretudo de experimentação. Mestrandos e doutorandos têm se lançado e se arriscado nessa dimensão metodológica, muito provavelmente em busca de outros caminhos do pensar e do fazer investigativo que se adequem aos seus raciocínios e ao seu modo de construir os objetos.

Possivelmente por ter se inserido no campo da Comunicação no Brasil há pouco tempo, os usos e apropriações das cartografias se direcionam mais a afirmar uma alternativa potente a pontos de vista teórico-metodológicos já existentes, o que permitiria traçar outros percursos investigativos. Essa relativa 'novidade', entretanto, não desobriga à problematização, à contextualização e à experimentação, muito menos libera da reflexão e dos processos de debate. 
Entendendo que esse pensamento não é apenas parte de um modismo, mostra-se a relevância de um aprofundamento teórico-empírico. Por esse ângulo, a multiplicação das investigações nessa área permitirá que o método delineie seus princípios, ao mesmo tempo que possibilitará aglutinar mais consensos sobre o processo. Não obstante, é preciso considerar em que medida o campo da Comunicação está interessado em dar atenção à fundamentação, à explicitação e ao debate acerca dos métodos e metodologias utilizados na área.

Deleuze e Guattari lembram que estamos acostumados a linhas de articulação ou segmentaridade, estratos e territorialidades que levam à configuração do pensamento e da análise das coisas por meio de modelos hegemônicos. No viés construído pela cartografia, é preciso um descolamento em relação a esses costumes, considerando também as linhas de fuga, os resíduos, os movimentos de desterritorialização e desestratificação.

É sob esse contexto de construção de conhecimento e investigação que teses e dissertações da área da Comunicação que escolhem a cartografia como método estão tentando se mover, ainda que de forma incipiente, sem total firmeza e com confiança restrita muitas vezes. Entendemos, todavia, que esse é o cenário enfrentado por exploradores e, por isso, entendemos que os trabalhos analisados trazem a semente da coragem metodológica (como provavelmente muitas outras pesquisas desenvolvidas no campo).

\section{Referências}

BARROS, L. M. R. de; BARROS, M. E. B. de. O problema da análise em pesquisa cartográfica. Fractal Revista de Psicologia. v. 25, n. 2, p. 373-390, maio/ago. 2013.

BENJAMIN, W. Obras Escolhidas, v. II, Rua de mão única, trad. de R.R. Torres F. e J.C.M. Barbosa, São Paulo: Brasiliense, 1987.

BENJAMIN, W. Magia e técnica, arte e política: ensaios sobre literatura e história da cultura. 8a. ed. revista. São Paulo: Brasiliense, 2012a.

BENJAMIN, W. Sobre arte, técnica, linguagem e política. Lisboa: Relógio D’Água Editores, 2012b.

BONIN, J. A. Explorações sobre práticas metodológicas na pesquisa em comunicação. Revista FAMECOS. n. 37, Porto Alegre, dez. 2008.

BRAGA, J. L. A prática da pesquisa em Comunicação: abordagem metodológica como tomada de decisões. E-compós. Brasília: Compós, v. 14, n. 1, 2011.

CORPUS CARTOGRAFIA DAS CONTROVÉRSIAS. Corporalidades. Disponível em: http://corporalidades. com.br/site/2019/02/20/2054/. Acesso em: 20 fev. 2019.

COSTA, L. B. da. Cartografia: uma outra forma de pesquisar. Revista Digital do LAV. Santa Maria, v. 7, n. 2, p. 66-77, maio/ago. 2014. Disponível em: https://periodicos.ufsm.br/revislav/article/view/15111/pdf_1. Acesso em: 18 jun. 2019.

DEBORD, G. Questões preliminares à construção de uma situação. In: JACQUES, P. B. (Org.). Apologia da Deriva: escritos situacionistas sobre a cidade. Rio de Janeiro: Casa da Palavra, 2003.

DELEUZE, G.; GUATTARI, F. Mil platôs. Capitalismo e esquizofrenia. v. 1. São Paulo: Ed. 34, 1995a.

DELEUZE, G.; GUATTARI, F. Mil platôs. Capitalismo e esquizofrenia. v. 2. São Paulo: Ed. 34, 1995b. 
DELEUZE, G.; GUATTARI, F. Mil platôs. Capitalismo e esquizofrenia. v. 3. São Paulo: Ed. 34, 1996.

DELEUZE, G.; GUATTARI, F. Mil platôs. Capitalismo e esquizofrenia. v. 4. São Paulo: Ed. 34, 1997a.

DELEUZE, G.; GUATTARI, F. Mil platôs. Capitalismo e esquizofrenia. v. 5. São Paulo: Ed. 34, 1997b.

DELEUZE, G.; GUATTARI, F. Mil platôs: capitalismo e esquizofrenia. v. 1, 2a. ed. São Paulo: Ed. 34, 2011.

FERREIRA, N. As pesquisas denominadas “Estado da Arte”. Educação e Sociedade, ano 23, n. 79, ago. 2002.

FEYERABEND, P. Contra o método: esboço de uma teoria anárquica da teoria do conhecimento. Rio de Janeiro: F. Alves, 1977.

FLICK, U. Introdução à pesquisa qualitativa. Porto Alegre: Artmed, 2009.

FOUCAULT, M. A hermenêutica do sujeito. São Paulo: Martins Fontes, 2006.

FOUCAULT, M. A ordem do discurso. 5a. ed. São Paulo: Loyola, 1996.

FOUCAULT, M. Microfísica do poder. 11a. ed. Rio de Janeiro: Graal, 1993.

GALINDO CÁCERES, J. Contextos ecológicos y sistemas de información y comunicación. Configuraciones, trayectorias, matrices situacionales y contextos de posibilidad en lo social. El caso de las redes de investigación. Revista Interamericana de Bibliotecología, Medellín, v. 24, n. 2, p. 56-91, 2001.

GUATTARI, F.; ROLNIK, S. Micropolíticas - cartografia do desejo. Petrópolis: Vozes, 1996.

GUMBRECHT, H. U. Produção de presença: o que o sentido não consegue transmitir. Rio de Janeiro: Contraponto, 2010.

KASTRUP, V. O funcionamento da atenção no trabalho do cartógrafo. Psicologia \& Sociedade. Associação Brasileira de Psicologia Social Minas Gerais, v. 19, n. 1, p. 15-22, jan./abr. 2007. Disponível em: http://www. redalyc.org/articulo.oa?id=309326394003. Acesso em: 18 jun. 2019.

KASTRUP, V. O método da cartografia e os quatro níveis da pesquisa-intervenção. In: CASTRO, L. R.; BESSET, V. L. (Orgs.). Pesquisa intervenção na infância e juventude. Rio de Janeiro: Nau, 2008. v. 1, p. 465-489.

KASTRUP, V.; PASSOS, E. Cartografar é traçar um plano comum. Fractal Revista de Psicologia, v. 25, n. 2, p. 236-280, maio/ago. 2013.

LATOUR, B. Reagregando o social. Salvador: EDUFBA, 2012.

LEMOS, A. A comunicação das coisas: teoria ator-rede e cibercultura. São Paulo: Annablume, v. 310, 2013.

LEMOS, A. A comunicação das coisas: internet das coisas e teoria ator-rede - etiquetas de radiofrequência em uniformes escolares na Bahia. In: SimSocial, Salvador, Bahia, out. 2012. Anais....

LEMOS, A. (Org.). Teoria ator-rede e estudos de comunicação. Salvador: EDUFBA, 2016

MARTÍN-BARBERO, J. Ofício de cartógrafo: travessias latinoamericanas da comunicação na cultura. São Paulo: Loyola, 2004.

MORIN, E. Introdução ao pensamento complexo. 4a. ed. Porto Alegre: Sulina, 2011.

OTTE, G.; VOLPE, M. L. Um olhar constelar sobre o pensamento de Walter Benjamin. Fragmentos. Florianópolis, n. 18, p. 35-47, jan./jun. 2000. Disponível em: https://periodicos.ufsc.br/index.php/fragmentos/ article/download/6415/5984. Acesso em: 16 jun. 2019. 
PASSOS, E.; KASTRUP, V.; ESCÓSSIA, L. Apresentação. In: Pistas do método da cartografia: pesquisaintervenção e produção de subjetividade. Porto Alegre: Sulina, 2009.

PASSOS, E.; KASTRUP, V.; ESCÓSSIA, L. Pistas do método cartográfico: pesquisa-intervenção e produção de subjetividade. Porto Alegre: Sulina, 2009.

PEREIRA, D. C.; BOECHAT, M. P. Apenas siga as mediações: desafios da Cartografia de Controvérsias entre a Teoria Ator-Rede e as mídias digitais. Contemporânea - Revista de Comunicação e Cultura, v. 12, n. 3, p. 556-575, 2015.

POPPER, K. A lógica da pesquisa científica. 2a. ed. São Paulo: Cultrix, 2013.

ROLNIK, S. Cartografia Sentimental da América: produção do desejo na era da cultura industrial. 250f. Tese. (Doutorado em Psicologia Social). Pontifícia Universidade Católica de São Paulo. Programa de PósGraduação em Psicologia Social, 1987.

ROLNIK, S. Cartografia sentimental. Transformações contemporâneas do desejo. Porto Alegre: Sulina; Editora da UFRGS, 2006.

ROSÁRIO, N. M. Cartografia na comunicação: questões de método e desafios metodológicos. In: PEIXOTO, C.; LOPES, M. I. V. Pesquisa em comunicação: metodologias e práticas acadêmicas. Porto Alegre: EDIPUCRS, 2016. p. 175-194.

ROSÁRIO, N. M. Mitos e cartografias: novos olhares metodológicos na comunicação. In: MALDONADO, A. E.; BONIN, J.; ROSÁRIO, N. M. (Orgs.). Perspectivas metodológicas em Comunicação: desafios na prática investigativa. João Pessoa: Editora UFPB, 2008.

ROSÁRIO, N. M.; AGUIAR, L. M. A cartografia como um processo teórico-metodológico multifacetado para estudos da cibercultura. In: VI SIMPÓSIO NACIONAL DA ASSOCIAÇÃO BRASILEIRA DE PESQUISADORES EM CIBERCULTURA (ABCiber), Novo Hamburgo: Universidade Feevale, 2012. Anais....

SANTOS, B. S. Introdução a uma ciência pós-moderna. Rio de Janeiro: Graal. 1989.

SILVEIRA, F. L. da. O olhar etnográfico de Walter Benjamin. In: XXV CONGRESSO BRASILEIRO DE CIÊNCIAS DA COMUNICAÇÃO - Salvador -BA - 1 a 5 de setembro de 2002. Anais.... Disponível em: http://www.portcom.intercom.org.br/pdfs/131467036819540624755434523387115016002.pdf. Acesso em: 16 jun. 2019.

VENTURINI, T. Diving in magma: how to explore controversies with actor-network theory. Public understanding of science, v. 19, n. 3, p. 258-273, 2010.

\section{Nísia Martins do Rosário}

Professora e pesquisadora no Programa de Pós-Graduação em Comunicação e no curso de Comunicação Social da Universidade Federal do Rio Grande do Sul (UFRGS). Doutora em Comunicação Social (PUCRS), mestre em Semiótica (UNISINOS), graduada em Comunicação Social - Jornalismo pela mesma instituição. Bolsista de Produtividade em Pesquisa (PQ), do CNPq. Apoio CAPES. Vice-presidente da COMPÓS (2019-2021); vice-coordenadora do PPGCOM (20192021). Membro dos grupos de pesquisa GPESC e PROCESSOCOM, que é organizador da REDE AMLAT. E-mail: nisiamartins@gmail.com. 


\section{Paula Coruja}

Doutoranda e mestra em Comunicação e Informação pelo Programa de Pós-Graduação em Comunicação da Universidade Federal do Rio Grande do Sul (PGCOM/UFRGS). Jornalista formada pela Universidade do Vale do Rio dos Sinos (Unisinos). Bolsista de doutorado do CNPq. Integra os grupos de pesquisa Comunicação e Práticas Culturais, da UFRGS, e Processocom, da Unisinos. E-mail: paula.coruja@gmail.com.

\section{Tiago Segabinazzi}

Mestre em Ciências da Comunicação pela Universidade do Vale do Rio dos Sinos (Unisinos) e jornalista pela Universidade do Vale do Taquari (Univates). Radialista na Rádio Univates FM 95.1. E-mail: tiagosegab@gmail.com.

Recebido em: 01.07.2020

Aprovado em: 06.02.2021 